EESTI NSV TEADUSTE AKADEEMIA TOIMETISED. 20. KOIDE KEEMIA * GEOLOOGIA. 1971, NR. 2

ИЗВЕСТИЯ АКАДЕМИИ НАУК ЭСТОНСКОН ССР. ТОМ 20 Химия * ГЕОЛОГИя. 1971, № 2

УдК 551.351

Н. АИБУЛАТОВ, К. ОРВИКУ мл.

\title{
О ВОЗМОЖНОСТЯХ ИСПОЛЬЗОВАНИЯ ПОДВОДНОИ ЛАБОРАТОРИИ «ЧЕРНОМОР» ДЛЯ ГЕОЛОГИЧЕСКИХ ИССЛЕДОВАНИЙ
}

Непосредственные подводные исследования геолого-геоморфологических процессов в морях и океанах в последнее время приобрели большую актуальность в связи с расширением и углублением задач по исследованию шельфа. Косвенные методы изучения современных геолотических процессов не всегда могут дать ответы на вопросы, связанные с определением абсолютной скорости осадкообразования, с изучением хода самого процесса во времени (сезон, год и т. д.).

В связи с этим в последнее время наблюдается заметная активизация в исследовании процессов седиментации методами непосредственных измерений, которые, в свою очередь, требуют вторжения ученого на дно моря.

До последнего времени ученые могли находиться на дне весьма незначительное время, так как работали в автономном снаряжении, связанном с поверхностью моря. Однако экспериментальные геологические измерения на дне требуют длительного пребывания исследователя в толще воды, ибо предварительная организация опытных полигонов, установка измерительных комплексов очень трудоемка. В таких случаях большую помощь могут оказать подводные лаборатории, детища 60-х годов, которые позволяют исследователю без ежедневной декомпрессии работать непосредственно у объекта днями и неделями. В данном случае применение подводной лаборатории удобно еще и потому, что на глубинах 20-40 $и$ исследователь может работать независимо от погодных условий на поверхности моря. Подводные лаборатории открывают широкую перспективу в проведении весьма тонких экспериментов в области седнментологии, в задачи которой входит исследование количественных характеристик процессов седиментации в море. Это потребует организации подводной триангуляционной сети, экспериментальных полигонов, опытных полос, протягивающихся перпендикулярно берегу на большие глубины, опытных прорезей и т. д.

ПІеред проведением наших исследований мы имели весьма скудные сведения о геологических работах в экспериментах «Преконтинент» и «Силаб» (Флехсиг, 1968). В статьях общего характера были скромные упоминания о визуальных наблюдениях в «Преконтиненте-2», об исследовании движения обломочного материала в каньоне Скринпса с помощью люминофоров. Интересных методических разработок в области литодинамики в литературных источниках нами не встречено, в связи с чем наши исследования из подводной лаборатории «Черномор» носили в основном экспериментально-методический характер. 
Подводная лаборатория была установлена в 1968 году в одной из бухт Черного моря. В геологическом отношении бухта приурочена к переходной зоне между различными структурами. Борта бухты представлены флишевыми породами, образующими клифы высотой до $20 \mathrm{M}$. Кутовая часть бухты сложена галечным материалом, ширина пляжа около $15-18$ м.

Подводный береговой склон в районе бухты довольно однородный, без резких изменений в рельефе, уклон дна в районе глубин $10-15$ ж составляет в среднем 0,017 . В верхней части бухты дно сложено грубозернистым крупнообломочным материалом (галька, гравий), далее, на глубине 5-7 м. идет среднезернистый песок со щебенкой, который, начиная с $7-8 \mu$ сменяется среднезернистым чистым песком. Песчаное поле более всего вытянуто в море в осевой части бухты. Здесь лишь на глубине $15 \mu$ песок сменяется битой и цельной ракушей. Граница ила близ бухты лежит на глубине около $40 \mathrm{\mu}$. По обе стороны бухты эта граница сдвигается резко к берегу. Близ бортов бухты хорошо выражены бенчи, имеющие грядовое строение.

Глубина постановки подводной лаборатории (12,5 м) позволяла акванавтам работать без каждодневной декомпрессии в диапазоне глубин от 6 до 25 , т. е. геологическая программа исследований касалась динамики рельефа и наносов в зоне песчано-ракушечного поля, котороє иногда нарушалось выходами коренных пород.

Место постановки лаборатории находилось мористее внешнего забурунивания волн (максимальная высота волн в бухте 4 м). В литодинамическом отношении эта зона шельфа изучена довольно слабо. Большинство исследований в этом направлении касается в основном зоны от первого забурунивания волн до пляжевой полосы. Это связано с большими техническими трудностями проведения таких работ вдали от берега, а также бытующими до настоящего времени представлениями о преобладании переноса материала именно в этой зоне. Между тем наши исследования (Айбулатов, 1968), а также некоторые литературные источники свидетельствуют о том, что нижняя граница переноса обломочного материала уходит на достаточно большие глубины шельфа.

Применение подводной лаборатории позволило поставить задачу измерения интенсивности процессов осадкообразования на инертных глубинах и для материалов, имеющих значительный диапазон изменения гранулометрического состава. Кроме того, была поставлена задача разработать методику подводных геологических исследований из обитаемых лабораторий.

Вырабатываемая методика исследований преследовала цель проследить на замаркированных заранее участках дна динамику рельефа, уловить изменения гранулометрии осадков в заранее закрепленных точках во времени и, наконец, получить эпюру разноса маркированного слол осадков и объем перемещающегося материала как в толще воды, так и непосредственно по дну.

Экспериментальные полигоны, на которых проводились указанные исследования, располагались на глубинах 10,15 и 20 м (рис. 1) и имели строение, изображенное на рис. 2. Квадрат со стороной 20 м разбивался на более мелкие квадраты со стороной 5 м. Каждая точка закреплялась репером (стальной прут) длиной 1,75 м, который забивался кувалдой до 0,75 м. На репер свободно одевался цилиндрический каркас из проволоки 0,3 мм, заканчивавшийся кольцами. Подразумевалось, что по мере размыва грунта близ репера каркас будет опускаться, фиксируя максимальный размыв грунта. Несмотря на возможный в дальнейшем намыв грунта в данном месте, благодаря таким каркасам мы могли фиксиро- 
вать нижнее положение донной поверхности, а в совокупности с замером самого репера - амплитуду деформации дна.

Разбивка полигона осуществлялась, при помощи фала длиной около $80 . \mu$ с метками через каждые 5 и и с петлями на концах через каждые 20 . На первый вбитый в грунт штырь, одевалась концевая петля и водолаз, идя по компасу, разматывал 20 м фала. Затем снова вбивался репер, надевалась петля и начиналась новая прокладка под углом $90^{\circ}$ к первоначальному направлению. Операция повторялась до замыкания границ квадрата. Затем проверялись углы и разбивка полигона продолжалась дальше. На эту операцию у двух человек в условиях видимости $0,5-1,5$ м затрачивалось около $20-25$ мин. Далее, по меткам фала через каждые 5 м вбивались реперы, после чего фал параллельно переносился на соседнюю пару

штырей, снова вбивались реперы и т. д. Эта операция занимала около 30 мин. Для облегчения установки штырей в условиях плохой видимости можно использовать рамку $5 \times 5 \mu$ из алюминиевых трубок, которая дает большую точность и ускоряет процесс разбивки полигонов. Каждый репер маркировался порядковым номером из пластика для облегчения работы акванавтов при повторных замерах.

В средней части каждого полигона монослоем было уложено два квадрата маркированного материала: галька, окрашенная в яркокрасный цвет (нитрокраской) и песок, окрашенный светло-желтым люминофором. Здесь же, в 20 см от поверхности дна, было установлено два взаимно контролирующих взвесеуловителя длительного заполнения.

После разбивки полигонов акванавтами около каждого репера были взяты пробы грунта колонковым отборником длиной 30 см и замерены высоты каждого репера. Дальнейшая работа, связанная с повторными замерами реперов, отбором проб и снятием взвесеуловителей проходила с поверхности эпизодически после значительных штормов или их серий.

K настоящему времени мы имеем еще недостаточное количество данных для получения хорошо обоснованных выводов, так как проведенные повторные измерения (без взятия проб для гранулометрического анализа) были выполнены пока один раз - спустя месяц после организащии полигонов. Несмотря на это, уже сейчас можно говорить о большой активности процессов осадкообразования на глубинах 10 и $15 \mu$. Так, например, на глубине $10 м$ за один месяц, т. е. по существу за два кратко- 


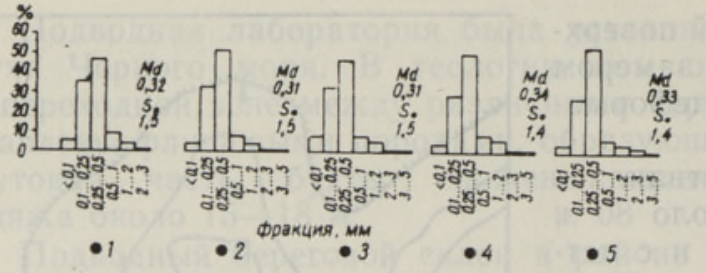

временных 4-балльных волнения, произошла повсеместная аккумуляция материала мощностью около 20 см. Объем принесенного на этот полигон обломочного материала составил $80 \mathrm{M}^{3}$. Нужно отметить исключитель ную равномерность слоя аккумуляции на полигоне, что свидетельствует о том, что вся площадь полигона в течение указанного периополигон ме

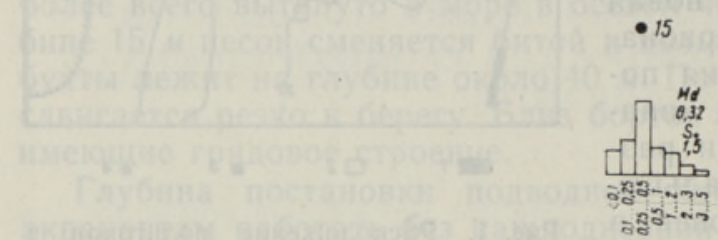

- 25
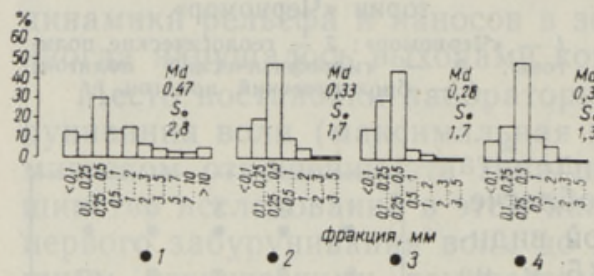

- 1

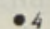

палигон на гл. $15 \mathrm{M}$

Рис. 3. Гистограммы механического состава грунтов на полигонах гл. 10 и $15 \mu$. да времени при данных метеорологнческих условиях располагалась в одной дннамической зоне.

На глубине $15 \mu$ также произошла повсеместная аккумуляция, хотя и меньших масштабов. Слой намыва составил на этом полигоне в среднем около $8 \mathrm{~cm}$. а объем принесенного материала - $32 \boldsymbol{n}^{3}$.

Приведенные данные по динамике рельефа дна на полигонах свидетельствуют о большой активности прочессов осадкообразования в нижней части береговой зоны. Трудно сейчас говорить о каких-либо закономерностях: возможно, в этом районе глубины $10-15$ м лвляются зоной стабильной аккумуляции материала, пришедшего со стороны берега, возможно, отмеченная аккумуляция носит временный характер, как результат действия разрывных течений.

В данном районе не раз отмечалось наличие мощных разрывных течений, направленных в сторону моря. Так, например, при одном 4-балльном волнении подводная лаборатория, нмеющая отрицательную плавучесті $3,9 \tau$, совершила против волнения «подводный рейд» длиной около $70 \mathrm{~s}$. Это движение «Черномора» мы склонны отнести к действию разрывных течений. Интересно, что лаборатория совершила этот путь не только периодически взвешиваясь под действием волнения, но и волоком, что сьидетельствует о высоких скоростях придонных разрывных течений в этом районе. Безусловно, такие течения довольно активно воздействуют на дно, вынося в кутэвую часть бухты значнтельную часть материала, отлагаемого в районе затухания течений (Айбулатов, 1966). Какое из этих двух предположений действительно имеет место - покажут дальнейшие исследования. Однако уже сейчас ясно: зона на глубинах 
$10-15 \mu$ не является инертной и ее изучение крайне необходимо как для понимания береговых процессов, так и для процессов, происходящих в средней и нижней части шельфа.

Представляет большой интерес проследить изменение механического состава наносов на полигонах в точках, отстоящих друг от друга на 5 м (рис. 3). На фоне общего однообразия наносов, слагающих полигоны (в основном фракция $0,25-0,50$ мм) наблюдается заметное различие (до $10 \%$ ) в механическом составе проб, взятых буквально в 5 м друг от друга. Это свидетельствует о слабой сортировке принесенных наносов, что опять же подтверждает высокую литодинамическую активность в зоне за внешним забуруниванием волн. Повторное взятие проб на полигонах укажет скорость изменения механического состава материала, которая явится критерием для определения скорости переформирования осадочной толщи.

В методическом отношении проведенные исследования поставлены правильно и дают возможность оценить интенсивность происходящих процессов осадкообразования в количественном отношении. Начатыє исследования необходимо продолжить, расширив их до глубин $30-40 \mu$. Именно на этих глубинах, по нашему мнению, и находится ннжняя граница береговой зоны, т. е. граница достаточно активных перемещений обломочного материаліа.

Кроме того, постановка лаборатории на глубинах до 40 и более мет ров позволит организовать исследование подводных каньнов. На вопрос: как и когда были созданы под водой такие формы донного рельефа? -мэжно дать ответ лишь после проведения детальных непосредственных исследований бортов и ложа каньонов (Каплин, 1961).

Современная динамика каньонов, которые, как показали последние исследования (Shepard, Dill, 1966; Егоров, Галанов, 1967), являются каналами стока для огромного количества терригенного материала, на наш взгляд, не может быть изучена вслепую с поверхности моря. Необходимы экспериментальные исследования вдоль тальвега каньона и по его бортам, установка точных датчиков скоростей, индикаторов переноса наносов, бурение толци осадков на склонах, т. е. необходимо присутствие исследователя в толще воды. Без применения обитаемых подводных лабораторий или других водолазных комплексов здесь не обойтись. Увеличению глубины проникновения ученого в каньоны могут содействовать пневмоубежища типа «Спрут», расположенные недалеко от основной подводной лаборатории, где акванавт может временно расположиться со своей аппаратурой.

Преимущество организации исследований подводных каньонов из: подводной лаборатории состоит в том, что исследователь, проводя наблюдення за реперами и повторные геодезические съемки, сразу получает количественные данные о происходящих там процессах.

Выполнение исследований вершин каньонов из подводной лаборатории «Черномор» на кавказском побережье Черного моря (например, в районе каньонов мыса Пицунда) позволит в ближайшем будущем получить уникальный материал по режиму каньонов, что значительно. приблизит нас к пониманню происхождения форм рельефа, а также внесет вклад в решение проблемы размыва черноморских берегов.

Существуют и другие аспекты применения подводных лабораторий для геологических целей (определение физико-механических свойств rрунтов in situ, динамика илов и т. д.). Однако в любом случае эффект: от применения подводной лаборатории будет болеє ощутим, если послед:няя используется в комплексе с другими геологическими методами, 
В заключение авторы выражают большую благодарность акванавтам первого геологического экипажа П. Боровикову, Б. Громадскому, О. Куприкову, Б. Москалекіко и Ю. Калинину. В состав этого экипажа входил и один из авторов (К. Орвику).

\section{ЛИТ Е Р А Т Р А}

Айбулатов Н. А. 1966. Исследование вдольберегового перемещения песчаных наносов в море. $M$.

А й $б$ ул атов Н. А. 1968. О динамике наносов в нижней части береговой зоны. Тр. Союзморниипроекта, № 20 (26).

Е горов Е. Н., Га ланов Л. Г. 1967. Исследование подводных каньонов. Океанология, № 4.

К а плин П. А. 1961. Водолазные исследования вершин подводных каньонов. Океанология, № 6.

Флехсиг А. О. 1968. Значение подводных лабораторий для науки. В сб.: Подводная лаборатория «Силаб-2». Л.

Shepard F., Dill R. 1966. Submarine canyon and other sea valleys. Rend McNelly and Co. Chicago.

Южное отделение Ннститута океанологии Акаделии наук СССР

Поступила в редакцию

Институт геологии

Академии наук Эстонской ССР

$6 / \mathrm{I} 1971$

N. AIBULATOV, K. ORVIKU jun.

\section{VEEALUSE LABORATOORIUMI «TŠERNOMOR» KASUTAMISEST GEOLOOGILISTEL UURIMISTEL}

Veealuse laboratooriumi «Tšernomor» katsetamisel 1968. aastal sooritati ka veealuseid geoloogilisi uurimisi.

Laboratooriumi viibimine $12,5 \mathrm{~m}$ sügavusel võimaldas akvanautidel ilma igapäevase dekompressioonita töötada $6-25 \mathrm{~m}$ sügavuses. 10,15 ja $20 \mathrm{~m}$ sügavusele rajati eksperimentaalsed polügoonid litodünaamilisteks uurimisteks. Artiklis on antud ülevaade nende polügoonide rajamisest ja veealuste geoloogiliste tööde metoodikast.

Uurimised näitasid settimisprotsessi suurt aktiivśust rannavööndi alumises osas. Artiklis on esitatud esimesed andmed nende setete kujunemise intensiivsuse kohta $10-15 \mathrm{~m}$ sügavuses, antud hinnang uuele veealuse geoloogia uurimismeetodile ja näidatud selle meetodi perspektiivsust.

N. AIBULATOV, K. ORVIKU jun.

\section{ON THE POSSIBILITY OF THE SUBMARINE LABORATORY "CHERNOMOR" FOR GEOLOGICAL RESEARCHES}

During a series of tests with the submarine laboratory "Chernomor", the authors also effected some submarine geological researches.

The position of the laboratory at a depth of $12.5 \mathrm{~m}$ enabled aquanauts to work without daily decompression at depths of $6-25 \mathrm{~m}$. At depths of 10,15 and $20 \mathrm{~m}$, experimental polygons were established for lithodynamic researches. The article presents a survey of the building of those polygons and discusses the methods of subaqueous geological work.

The researches proved the considerable intensity of the sedimentational process in the lower part of the near-shore zone. The authors present the first data on the intensity of sedimentation at a depth of $10-15 \mathrm{~m}$, give their views on the new method of subaqueous geological researches and show its possibilities in the future. 